\title{
openheart Interpreting angina: symptoms along a gender continuum
}

\author{
Catherine Kreatsoulas, ${ }^{1}$ Mary Crea-Arsenio, ${ }^{2}$ Harry S Shannon, ${ }^{2}$ \\ James L Velianou, ${ }^{2,3}$ Mita Giacomini ${ }^{4}$
}

To cite: Kreatsoulas C,

Crea-Arsenio M,

Shannon HS, et al.

Interpreting angina:

symptoms along a gender

continuum. Open Heart

2016;3:e000376.

doi:10.1136/openhrt-2015000376

- Additional material is available. To view please visit the journal (http://dx.doi.org/ 10.1136/openhrt-2015000376).

Received 27 November 2015 Revised 8 February 2016 Accepted 23 February 2016

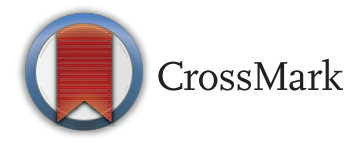

${ }^{1}$ Harvard TH Chan School of Public Health, Cambridge, Massachusetts, USA

${ }^{2}$ Faculty of Health Sciences, McMaster University, Hamilton, Ontario, Canada ${ }^{3}$ Interventional Cardiology, Hamilton General Hospital, Hamilton, Ontario, Canada ${ }^{4}$ Faculty of Health Sciences, McMaster University, Centre for Health Economics \& Policy Analysis, Hamilton, Ontario, Canada

Correspondence to Dr Catherine Kreatsoulas; ckreats@hsph.harvard.edu

\section{ABSTRACT}

Background: 'Typical' angina is often used to describe symptoms common among men, while 'atypical' angina is used to describe symptoms common among women, despite a higher prevalence of angina among women. This discrepancy is a source of controversy in cardiac care among women.

Objectives: To redefine angina by (1) qualitatively comparing angina symptoms and experiences in women and men and (2) to propose a more meaningful construct of angina that integrates a more gender-centred approach.

Methods: Patients were recruited between July and December 2010 from a tertiary cardiac care centre and interviewed immediately prior to their first angiogram. Symptoms were explored through in-depth semistructured interviews, transcribed verbatim and analysed concurrently using a modified grounded theory approach. Angiographically significant disease was assessed at $\geq 70 \%$ stenosis of a major epicardial vessel.

Results: Among 31 total patients, 13 men and 14 women had angiograpically significant CAD. Patients describe angina symptoms according to 6 symptomatic subthemes that array along a 'gender continuum'. Gender-specific symptoms are anchored at each end of the continuum. At the centre of the continuum, are a remarkably large number of symptoms commonly expressed by both men and women.

Conclusions: The 'gender continuum' offers new insights into angina experiences of angiography candidates. Notably, there is more overlap of shared experiences between men and women than conventionally thought. The gender continuum can help researchers and clinicians contextualise patient symptom reports, avoiding the conventional 'typical' versus 'atypical' distinction that can misrepresent gendered angina experiences.

\section{INTRODUCTION}

Cardiovascular disease (CVD) is the leading cause of morbidity and mortality in the western world, and among patients with established CVD, mortality rates among women are equal to ${ }^{12}$ or exceed those in men. ${ }^{3}$ Despite women's $50 \%$ lifetime risk of dying from $\mathrm{CVD},{ }^{45}$ and higher prevalence of

\section{KEY QUESTIONS}

What is already known about this subject?

- It is widely believed that angina symptoms are different in men and women, often reinforced by terms such as 'typical angina', describing symptoms common in men, and 'atypical angina', describing symptoms common in women, despite a higher prevalence of angina in women worldwide. As a result, there is much controversy regarding angina symptoms, particularly among women.

What does this study add?

- This study presents a new framework for both clinicians and cardiac researchers to understand how patients experience angina symptoms along a 'gender continuum' as expressed in patients' natural language.

How might this impact on clinical practice?

- This study can help clinicians better contextualise and interpret their patients' symptom reports, pinpointing similarities, as well as differences in the language men and women use, challenging conventional medical terminology of 'typical' versus 'atypical' angina, which misrepresent gendered angina experiences.

angina, ${ }^{6}$ there remains a perception that CVD is a 'man's disease'.

Over the past half century, this misperception has led to the underappreciation, underrecognition and underdiagnosis of CVD in women, resulting in less medical therapy and fewer invasive procedures compared with men. ${ }^{7-15}$ This difference in care is often interpreted as the 'sex/gender bias', and we posit it is a result of confusion surrounding gender-typical symptomology, secondary to systemic exclusion/poor representation of women in research studies. Historically, early studies of angina were comprised mostly of men, and whether we realise this today or not, our understanding of angina is based on an underlying male construct. ${ }^{16}{ }^{17}$ Further fortifying the male-centric construct, women were excluded from many early published 
studies, $^{18} 19$ even among large landmark trials ${ }^{20-22}$ including studies on which the current gold standard for angina classification were developed and validated. ${ }^{16}{ }^{23}$ While CVD was assumed to progress similarly in women, when discrepancies in the disease presentation occurred, women were characterised as 'uncomplicated', ${ }^{1724-26}$ or labelled as 'atypical', implying, 'atypical compared to men'. ${ }^{, 27}$ As a result, the term 'atypical angina' is used today to describe symptoms common in women; however, this term is framed on exclusion criteria with no clear definition even among clinical guidelines. ${ }^{28} 29$ As a result, this lack of clarity and erroneous assumptions in the historical construction of angina symptomology likely contributes to the contemporary sex/gender bias seen in the cardiac care of women today.

\section{Sex and gender: what is the difference?}

While the terms sex and gender are often used interchangeably, the concepts they represent are not: sex is defined as the biological differences between females and males, including reproductive, anatomical and physiological differences', while gender refers to the array of socially constructed roles, relationships, beliefs, norms, attitudes, behaviours, values and relative power that society ascribes to the two sexes on a differential basis. ${ }^{30-32}$ Thus, 'aspects of sex will not vary substantially between different human societies, while aspects of gender may vary greatly' ${ }^{33}$ Differences in how angina manifests in men versus women depend on bodily sex differences and culturally gendered patient experiences and language expression.

\section{Study objectives}

To better understand angina in women and men, it is necessary to redefine the angina construct in genderrelevant terms. Qualitative methodology is ideally suited to explore and capture the interplay of individual patient experiences, symptomology and perceptions of cardiac-related pain in a language meaningful within their respective genders. ${ }^{34-39}$ The study objectives include: (1) to qualitatively compare angina and associated symptoms between women and men referred for coronary angiography, using a gender-centred approach and (2) develop a new construct of angina for women that is meaningful in terms of gender-centred experiences and in the language patients use to describe symptoms.

\section{METHODS}

This study adapted grounded theory methodology to understand patient experiences. ${ }^{37} 3840$ Study participants were recruited from the Hamilton Health Sciences, a tertiary cardiac care centre serving a population of over 2 million. To capture cardiac patients across the broad symptomatic presentation of angina we included elective and in-hospital patients referred for their first diagnostic coronary angiogram. We used theoretical purposeful sampling and interviewed men and women immediately prior to undergoing coronary angiography, to prospectively capture their symptoms without influence from knowledge of their angiographic results. We recruited primarily by gender, but purposefully sought a diverse group of patients in terms of age, with an approximately equal representation of women and men. ${ }^{37} 40$ The study was reviewed and approved from the McMaster University/Hamilton Health Sciences Research Ethics Board. All study participants provided informed consent.

\section{Inclusion/exclusion criteria}

Eligible participants were referred for coronary angiography for a primary diagnosis of suspected coronary artery disease (CAD) and had at least one prior abnormal test such as exercise stress test, nuclear imaging, electrocardiogram changes or elevated troponin. Patients were excluded if they were referred for valvular disease, arrhythmia, preoperation, had prior evidence of a myocardial infarction, had undergone previous coronary artery bypass graft surgery, percutaneous coronary intervention or were unable to communicate in English.

\section{Data collection}

Patient symptoms and perceptions of their symptoms were explored using in-depth semi-structured interviews (see online supplementary appendix A). Patient characteristics including demographics, cardiac risk factors and angiographic outcomes were also collected. Data collection continued until analytic saturation was reached. Interviews, ranging $12-50 \mathrm{~min}$ in length, were audio-recorded and transcribed verbatim. The interviewer also collected field notes with supplementary observations after each interview.

Following the interview, patients underwent coronary angiography according to standard of care. An experienced angiographer blindly interpreted angiographic images. Only patients with obstructive CAD were included in our analysis, defined as at least one vessel $>2.0 \mathrm{~mm}$ with $\geq 70 \%$ lesion stenosis.

\section{Qualitative data analysis}

NVivo-8 software (QSR International Pty Ltd, Australia) was used for data coding, and the analysis followed staged coding conventions (initial open coding, axial, theoretical coding) consistent with grounded theory. ${ }^{37}$ Initial coding was collaborative, involving three investigators (CK, MC, MG). Constant comparison was used to relate emerging categories to the data, checking each coded datum with the rest of the data to establish analytic categories. ${ }^{40}$ Analyses were considered 'saturated' when sufficient data supported key categories and new data did not further challenge or develop the grounded theory. 


\section{STUDY RESULTS}

\section{Description of study population}

The total study population consisted of 17 women and 14 men, of which 14 women and 13 men had obstructive $\mathrm{CAD}$. The mean age was 66 years (range 4484 years) for women and 60 years for men (range 38-71 years). Women reported a higher risk factor burden than men, where all women reported at least three CVD risk factors and all men reported at least one CVD risk factor.

\section{Main study findings}

When patients freely described their symptoms, symptoms were described along two main themes; 1) physical symptoms and 2) descriptors and hypotheses/analogies, with six sub-themes (table 1). Our gender-centred analysis revealed that cardiac-related symptoms array along a gender continuum. Represented and anchored on one end of the continuum are experiences reported mostly by men, and anchored at the opposite end of the continuum are experiences mostly reported by women. The term 'shared experience' is situated in the centre of the continuum to represent the overlap of symptoms expressed by both men and women (figure 1).

\section{Location of chest pain/discomfort}

Men and women commonly reported a type of 'pain' in the chest region, although they sometimes preferred to use other descriptive terminology to best capture their sensation. Pain/discomfort in the chest region was reported as being localised in the central chest area or to the right of centre (figure 2). There were no differences in the location of chest pain between men and women (figure 1).

\section{Non-chest localised areas of pain/discomfort}

Men and women described arm pain as localised at top of the arms, a tingling sensation in the left arm, right arm weakness and/or pain in both arms up to the elbows/bicep area. Pain/discomfort in the back was described as centred in the upper back, spanning across from shoulder to shoulder, or as a backache in the upper mid-back. Women additionally reported neck

Table 1 Main themes and subthemes of gender-centred angina symptomology

\begin{tabular}{|c|c|}
\hline Main theme & Subthemes \\
\hline Physical symptoms & $\begin{array}{l}\text { Location of chest pain/ } \\
\text { discomfort } \\
\text { Non-chest localised areas of } \\
\text { pain/discomfort } \\
\text { Other associated symptoms } \\
\text { Functional symptoms }\end{array}$ \\
\hline $\begin{array}{l}\text { Descriptors and } \\
\text { hypotheses/analogies }\end{array}$ & $\begin{array}{l}\text { Descriptors of pain/discomfort } \\
\text { Symptom hypotheses }\end{array}$ \\
\hline
\end{tabular}

pain and tightness in the throat. Men in our study did not report any unique localised areas of pain/discomfort (figures 1 and 2).

\section{Other associated symptoms}

In addition to localised areas of pain, almost all women and men reported shortness of breath with some difficulty breathing and periods of profuse sweating followed by coldness/clamminess with their localised pain. Men expressed 'feeling pale' and 'feelings of aggravation'. Women provided detailed accounts of many other concurrent symptoms including dizziness, weakness, sweating at night, feeling faint/fainting, fatigue, dry mouth, confusion, anxiety and panic. Women would often recall other associated symptoms throughout the interview, even when discussing other topics (figures 1 and 2).

\section{Functional symptoms}

Almost all patients in our study complained of shortness of breath, especially on exertion, often accompanied by chest pain/discomfort. Most patients reported experiencing shortness of breath for some time before seeking medical attention (figure 1). However, patients reported stopping, slowing down, limiting or avoiding physical activity altogether when experiencing or anticipating 'shortness of breath'. Older patients often decreased overall activity to avoid this symptom (figure 2).

\section{Descriptors of pain/discomfort}

Men and women had distinct differences in the terms they used to capture their pain/discomfort. Overall, men used succinct language to report their symptoms. Men would report 'chest pain', often qualifying their pain/discomfort with terms such as 'not severe, uncomfortable' and 'not a huge pain'. Women and men commonly emphasised that it was 'not a sharp pain', 'it was more of a tightness', 'discomfort', 'a very funny pain'. There was some unwillingness to commit to use the term 'pain' to describe their sensation, correcting the attending clinician's use of the term, 'pain', opting for more preferred terms such as 'discomfort', 'pressure', 'tightness' and 'weakness' (figure 2). Women would spend more time than men searching for a more accurate descriptive term to capture their sensation, and most often described it as a 'pressure'. The expansiveness of chest 'pain' descriptions increase along the gender continuum, with women using a greater number of descriptive terms to describe their pain compared to men (figures 1 and 2).

\section{Symptom hypotheses}

Interviews were conducted immediately prior to angiography to explore symptoms prospectively, before potentially influenced by angiographic results. Patients often had a working hypothesis to the cause of their pain and often used hypotheses/analogies to compare their pain to some other pain familiar to them. The most common hypotheses for men and women include 
Figure 1 Symptomatic subthemes along gender continuum.

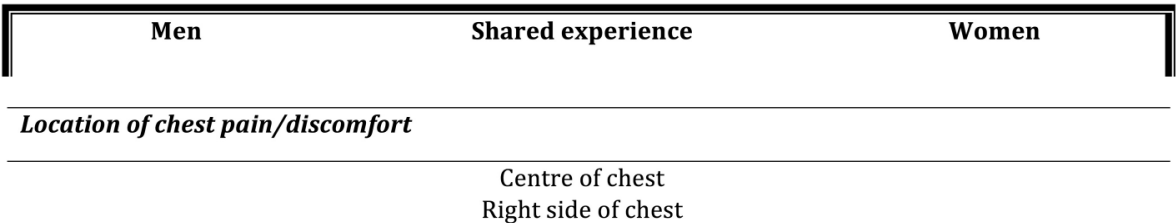

Right side of chest

Non-chest localized areas of pain/discomfort

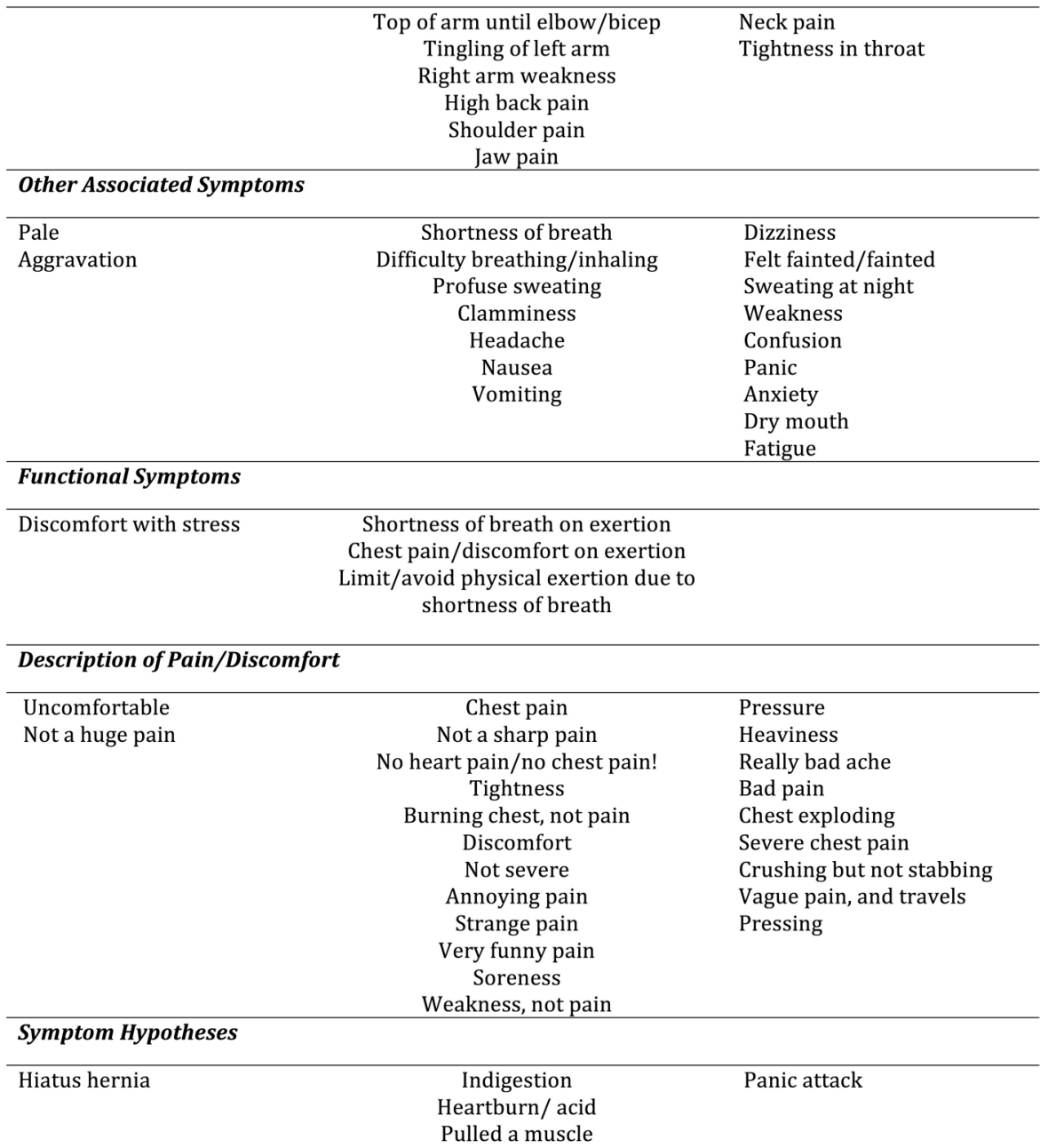

indigestion, heartburn or muscle strain. In addition, several men thought their symptoms may be attributed to hiatus hernia and several women said it felt like a panic attack (figures 1 and 2).

\section{DISCUSSION}

Our study sought to gain a deeper understanding of the cardiac-related angina symptoms that patients experience from a gender-centred perspective. When patients freely expressed their symptoms with minimal interview structure, two main themes emerged; 1) physical symptoms and 2) descriptors and hypotheses/analogies. Physical symptoms were subcategorised into four subthemes, including location of chest and non-chest areas of pain/discomfort, other associated symptoms and functional symptoms. We arrayed these symptoms on a 'gender continuum' that clarifies how women and men express symptoms in similar ways as well as differently (figure 1). We found considerable overlap in the shared symptomology between men and women. For this reason, we purport that the inflexible categorisation of symptoms according to sex does not accurately reflect the diversity among individuals, and especially within the sexes. Our new 'gender continuum' construct of angina symptomology demonstrates that a patient's sex can differ from their gendered expression of symptoms. More pointedly, the term 'atypical' angina to represent symptoms in women is challenged by this empirically grounded continuum: both men and women experience a great number of conventionally 'atypical' as well as 'typical' angina symptoms.

\section{Not so 'typical'}

Over the past half century, the term 'typical angina' has come to represent the cardiac-related symptoms most 
Location of chest pain/discomfort

"I was confused because I had a previous impression that heart symptoms were located exclusively on left side, and pain was on right side of chest; checked the internet which said, pain in the chest (not on a specific side) and decided to check it out."

\section{Non-chest localised areas of pain/discomfort}

"The main issue was the shortness of breath due to the chest pains but I could feel it go from my chest, basically the centre, and across my shoulders to the other side, across my upper back. It was like an elastic band. That's what it felt like. And then if I stopped doing what I'm doing, then it would be like, like letting go of the elastic. It felt like at the same time they were squeezing towards the middle, right across the upper back." (Woman, Age 48)

"I have very severe pain down both arms, it was very bad, bad, bad pain. It was the worse thing I ever had. It was very painful pressure, like my chest was going to explode." (Woman, Age 75).

\section{Other Associated Symptoms}

"The pain wasn't exactly in my tummy, like right in my stomach, it was right here [pointing to the centre of his chest]. I threw up, I thought it seems funny but I wanted to throw up. And then I started to sweat. After I threw up, the pain didn't go away, it started to get worse." (Man, Age 69)

"I couldn't take it anymore, I was having difficulty breathing and I sat down in a bus shelter. I just saw that I was sweating and by the time I decided I better get on home it was 9:30 at night promptly. The walls [of the bus shelter], the glass walls were just dripping and running from my wet perspiration. Unbelievable! (Woman, Age 71)

\section{Functional Symptoms}

"At my home there's two stories and there is 14 stairs from, from the rec room to the main floor. And then there's 14 stairs from there to go up to the bedroom. And that's when I used to notice, when I leave my rec room to go upstairs to bed at night. If I climb the 14 stairs twice, without stopping, by the time I get upstairs I would have the pain in my chest. I just sold my house and I'm moving in a month to a house with no stairs!" (Man, Age 66)

"I have had shortness of breath on exertion for a long time. I have shortness of breath when I'm going up and down the stairs too many times, if I'm walking or going a certain distance." (Woman, Age 48)

"The chest pain, or rather the slight pain, or uncomfortable feeling in the chest, especially on the treadmill. It feels tight with difficulty breathing. The difficulty breathing results in not wanting to carry on doing walking/activity." (Man, Age 68)

\section{Descriptors of pain/discomfort}

"It wasn't... it wasn't a pain though... well you wouldn't think it was a heart pain of any type... No real symptoms, but over the past few years I feel a bit of tightness with work" (Man, Age 49).

One woman, age 84, sought to correct the "pain" label;

"I felt weak. Very weak. So weak, I couldn't go... But no! No! I had no pain to speak of! I cannot say that I had any pain! I had a little bit of pressure on my chest sometimes and my breathing was not perfect..." (Woman, Age 84)

Another woman, age, 44, also corrected the "pain" label;

"I woke up with a really bad pressure, really bad pressure. It wasn't a pain, it was a pressure. It was annoying, but it wasn't a pain. They ask me all the time, "How's your pain?" but it's not really a pain, I don't know how to compare it but it's not severe." (Woman, Age 44)

\section{Symptom Hypotheses}

"You wouldn't think it was heart pain of any type, it was more like indigestion." (Man, Age 49)

"It feels like an acid, a burning in your chest, especially when walking around. I went to the doctor and he gave me these little stomach pills but they didn't do anything." (Woman, Age 83)

"At first it was really just uncomfortable and I thought well I just strained something or I pulled a muscle. I also thought I maybe had heartburn because it just felt wrong. So I you know, took some eno and that didn't help much with anything; I burped a few times but nothing much, pain was still there." (Woman, Age 58)

Figure 2 Excerpts from Interviews According to Symptomatic Subthemes.

commonly reported by men, while 'atypical angina' has come to represent the symptoms most common in women. While the historical gold-standard comparison group of 'typical' angina has been represented by white middle-aged males, ${ }^{16-27}$ it is not surprising that angina symptoms experienced among other groups are referred to as 'atypical'. Further, there are inherent conceptual limitations embedded within the 'atypical' label itself; 'atypical' has connotations implying 'abnormal, uncharacteristic, unusual and uncommon'. Presumably, one who symptomatically presents with 'typical' angina symptoms should receive 'typical' treatment; might the label 'atypical' be more permissive of 'atypical' treatment? May this, in part, explain why women are referred less 
than men for invasive procedures despite having severe symptoms? ${ }^{13} 14{ }^{41-45}$ As the label 'atypical' has become a catchall phrase for anyone who does not present as a 'typical', white, middle-aged male, the term may perpetuate poor classification of diverse angina patients and support sloppy science. We question the continued use of this institutionalised yet imprecise, and potentially misleading term.

\section{What does 'gender' have to do with it?}

While 'gender' has been on the forefront of many cardiac symptom studies, none to our knowledge have undertaken a gender, as opposed to sex, analysis. Most studies use the term 'sex' and 'gender' interchangeably, while technically referring to sex only. We raise this issue as one that goes beyond semantics: the binary construct of 'sex' cannot account for the complexity of gender phenomena. Analytically, this translates to two inherent limitations when analysing cardiac symptomology according to 'sex': (1) it underappreciates symptoms common to both sexes and (2) it cannot capture variation of symptoms within sex. Future studies should account for the role of gender, beyond sex, by capturing the full range of experiences in women and men.

We propose the gender continuum as a new construct to evaluate angina symptoms. When we array angina along the gender continuum, two main findings emerge: (1) men and women share more symptoms in common than conventionally believed and (2) there is great variation both between and within genders in the descriptive terms patients use to describe pain/ discomfort, and the reporting of other associated symptoms.

Gender is a complex and non-static social construct that interacts with other dimensions including social status, ethnicity, age, class and power. ${ }^{46}{ }^{47}$ An individual's gendered identity is often expressed through language and narrative, ${ }^{32}{ }^{46-50}$ such as a clinical history. It has been well described in the sociolinguistics literature that women tend to use a wider range of linguistic variation marked with a greater emotional vocabulary, conversationally using more of a 'rapport style' as opposed to 'report-style' common with men. ${ }^{32} 46-485051$ Most men in our study described their symptoms in briefer language than women used. Women provided detailed descriptions of their pain and associated symptoms, trying to capture the exact quality of their experience, fine tuning their choice of words as the interview progressed. These differences of language may reflect men and women's' differing social roles, and language subculture of expressing pain. Nevertheless, an expressive style is not exclusive to women, and this is the strength of the gender continuum: individuals may linguistically express themselves in a gender that differs from their sex. In a sociolinguistic study of patient narratives, significant variation was found within gender groups, especially among men, denoting that higher-status men were more likely to adopt a 'modern masculinity' marked by an emotional vocabulary comparable with women's. ${ }^{52} 53$ We found this with some men in our study, particularly young men ( $\leq 50$ years) and two older widowers, whose wives had succumbed to heart disease. We, like others, ${ }^{15}$ also heard more associated symptoms reported by women, perhaps, in part, due to their 'rapport-style'.

An important component of language and gender is that linguistic usage varies according to contextual factors, ${ }^{31} 32 \quad 46-485154$ such as the gender or the gendered style of the clinician. While outside the focus of the current study, our field notes included some observations related to clinician gender. Often a clinician would approach the patient with the question, 'Can you tell me about your chest pain?' to which patients commonly responded, 'Well, I wouldn't call it a pain, it was more pressing' or 'It is more of a discomfort than a pain'. The clinician would then in his/her notes write, ' 0 CP', which stands for 'No chest pain'. What happened in this interaction, and is the patient experiencing pain or not? The clinician began their consult posing a question about 'pain'. From a clinical perspective, 'pain' is a component of 'typical angina'-anything not described as 'pain' deviates from 'typical'. In this interaction, the clinician did not qualify the other terms used by the patient as describing 'chest pain'. At the same time, each patient has a sensation and reference point of what they qualify as 'pain', and since all the patients in our study were being investigated for $\mathrm{CAD}$, patients may also have preconceptions-as well as gendered ideas-of what heart pain should feel like. Like the patient, the clinician is also situated in their gender, within their roles, beliefs, norms, expectations, clinical training and experience not only about their own gender, but also of others'. Experimental studies have tested clinicians' gender bias using identical vignettes of patients that vary only by sex, and physicians consistently refer female patients less for cardiac catheterisation than their male counterparts. ${ }^{55} 56$ And while gender bias in patient referral for cardiac catheterisation has been reported irrespective of physician sex ${ }^{57}$ almost $90 \%$ of cardiologists in the USA and Canada are men ${ }^{58}$ and physician gender, to our knowledge, has never been evaluated. To fully consider gender, it is essential to understand that it is dynamic, and is happening simultaneously from the patient and clinician perspectives.

\section{Study limitations}

In order to achieve a fresh in-depth exploration of CAD symptoms less influenced by prevailing gender-biased clinical perspectives, we used an experienced interviewer who is not a clinician. Even so, it is possible that the clinical setting of the interview cued interviewers or patients to use what they considered more clinical-sounding terms or ideas. Also, a female interviewer conducted all interviews, and since patients are situated according to their gender, they may respond differently to an interviewer of their own sex versus the opposite sex. It is possible that same-gendered interviewers may elicit slightly different 
language or information than opposite-gendered interviewers. If this bias pertained, however, it would have favoured the female perspective, which was the underrepresented voice we especially sought to understand.

We recognise that gender is a social construct that likely interacts with many other factors such as ethnicity and socioeconomic position (SEP). For example, it is plausible that a population within a certain SEP may express more shared experiences, or that cultural groups with lower expressed emotion may express their symptoms differently. The next steps in the development of the gender continuum should include a similar evaluation in populations of diverse SEP and ethnicity.

\section{Conclusions and future directions}

We developed a new conceptual framework of angina, arraying patient experiences and symptoms along a 'gender continuum', and uncovered substantial shared experiences between men and women. This new 'gender continuum' of angina symptomology can help researchers and clinicians contextualise patient symptom reports. Customary labels of 'typical' and 'atypical' angina should be abandoned in favour of more descriptive and gender-relevant categories. In future research, we hope our angina construct is expanded among other cultural, socioeconomic and ethnic groups.

Acknowledgements The authors would like to thank Carolyn Lee, Alison Lee and Amanda Ormerod for their assistance in transcribing interviews.

Contributors CK conceived and designed the study, recruited patients, conducted the analysis and interpretation of data, developed the intellectual content, wrote the submitted manuscript, revised and approved the final version to be published. CK is also the overall content guarantor of the study, accepts full responsibility for the work and/or the conduct of the study, has access to the data, and controlled the decision to publish. This author takes responsibility for all aspects of the reliability and freedom from bias of the data presented and their discussed interpretation. MC-A contributed to qualitative study expertise, including design, analysis and interpretation of data, data collection guidance, critical revision for important intellectual content and final approval of the version to be published. HSS helped to conceive study design, refinement of study design, data analysis and interpretation of the data, critical revision for important intellectual content, supervisory role and final approval of the version submitted. JLV contributed to content expertise, conception of study design, read and interpreted the angiograms, critical revision for important intellectual content and final approval of the version submitted. MG helped to conceive study design, qualitative study expertise, including qualitative study design, analysis and interpretation of data, critical revision for important intellectual content, supervisory role and final approval of the version submitted.

Competing interests None declared.

Ethics approval McMaster University/Hamilton Health Sciences.

Provenance and peer review Not commissioned; externally peer reviewed.

Data sharing statement No additional data are available.

Open Access This is an Open Access article distributed in accordance with the Creative Commons Attribution Non Commercial (CC BY-NC 4.0) license, which permits others to distribute, remix, adapt, build upon this work noncommercially, and license their derivative works on different terms, provided the original work is properly cited and the use is non-commercial. See: http:// creativecommons.org/licenses/by-nc/4.0/

\section{REFERENCES}

1. American Heart Association. American Heart Association Heart and Stroke Statistics-2009 update. 2009.

2. Statistics C. Mortality, summary list of causes. Vol 2011. Ottawa, Canada: Minister of Industry, 2010.

3. Office for National Statistics. Deaths registered in England and Wales in 2010, by cause. 2011. http://www.ons.gov.uk/ons/rel/vsob1/ mortality-statistics--deaths-registered-in-england-and-wales--seriesdr-/2010/stb-deaths-by-cause-2010.html-tab-Leading-causes-ofmortality-in-2010

4. Mosca L, Jones WK, King KB, et al. Awareness, perception, and knowledge of heart disease risk and prevention among women in the United States. Arch Fam Med 2000;9:506-15.

5. Dische S. Assessing the odds. Lancet 1998;350:1563.

6. Hemingway $\mathrm{H}$, Langenberg $\mathrm{C}$, Damant $\mathrm{J}$, et al. Prevalence of angina in women versus men: a systematic review and meta-analysis of international variations across 31 countries. Circulation 2008;117:1526-36.

7. King KM, Ghali WA, Faris PD, et al. Sex differences in outcomes after cardiac catheterization: effect modification by treatment strategy and time. JAMA 2004;291:1220-5.

8. Anand SS, Xie CC, Mehta S, et al. Differences in the management and prognosis of women and men who suffer from acute coronary syndromes. J Am Coll Cardiol 2005;46:1845-51.

9. Ayanian JZ. Increased mortality among middle-aged women after myocardial infarction: searching for mechanisms and solutions. Ann Intern Med 2001;134:239-41.

10. Lagerqvist B, Safstrom K, Stahle E, et al., FRISC II Study Group Investigators. Is early invasive treatment of unstable coronary artery disease equally effective for both women and men? FRISC II Study Group Investigators. J Am Coll Cardiol 2001;38:41-8.

11. Malenka DJ, Wennberg DE, Quinton HA, et al. Gender-related changes in the practice and outcomes of percutaneous coronary interventions in Northern New England from 1994 to 1999. J Am Coll Cardiol 2002;40:2092-101.

12. Roger VL, Farkouh ME, Weston SA, et al. Sex differences in evaluation and outcome of unstable angina. JAMA 2000;283:646-52.

13. Johnston N, Bornefalk-Hermansson A, Schenck-Gustafsson $\mathrm{K}$, et al. Do clinical factors explain persistent sex disparities in the use of acute reperfusion therapy in STEMI in Sweden and Canada? Eur Heart J Acute Cardiovasc Care 2013;2:350-8.

14. Poon S, Goodman SG, Yan RT, et al. Bridging the gender gap: Insights from a contemporary analysis of sex-related differences in the treatment and outcomes of patients with acute coronary syndromes. Am Heart J 2012;163:66-73.

15. Khan NA, Daskalopoulou SS, Karp I, et al. Sex differences in acute coronary syndrome symptom presentation in young patients. JAMA Intern Med 2013;173:1863-71.

16. [No authors listed]. Coronary artery surgery study (CASS) Investigators. Coronary artery surgery study (CASS): a randomized trial of coronary artery bypass surgery. Survival data. Circulation 1983;68:939-50.

17. Proudfit WL, Shirey EK, Sones FM Jr. Selective cine coronary arteriography. Correlation with clinical findings in 1,000 patients. Circulation 1966;33:901-10.

18. Baird KL. The new NIH and FDA medical research policies: targeting gender, promoting justice. J Health Polit Policy Law 1999;24:531-65.

19. O'Donnell S, Condell S, Begley CM. 'Add women \& stir'--the biomedical approach to cardiac research! Eur J Cardiovasc Nurs 2004;3:119-27.

20. Gordon DJ, Rifkind BM. High-density lipoprotein-the clinical implications of recent studies. N Engl J Med 1989;321:1311-16.

21. [No authors listed]. Multiple risk factor intervention trial. Risk factor changes and mortality results. Multiple Risk Factor Intervention Trial Research Group. JAMA 1982;248:1465-77.

22. Pocock SJ, Shaper AG, Phillips AN, et al. High density lipoprotein cholesterol is not a major risk factor for ischaemic heart disease in British men. BMJ 1986;292:515-19.

23. Campeau L. Letter: Grading of angina pectoris. Circulation 1976;54:522-3.

24. Campeau L, Bourassa MG, Bois MA, et al. Clinical significance of selective coronary cinearteriography. Can Med Assoc J 1968;99:1063-8.

25. Dawber TR, Moore FE, Mann GV. Coronary heart disease in the Framingham study. Am J Public Health Nation's Health 1957;47(Pt 2):4-24.

26. Kannel WB, Castelli WP. The Framingham study of coronary disease in women. Medical Times 1972;100:173-5. passim. 
27. Kannel WB, Feinleib M. Natural history of angina pectoris in the Framingham study. Prognosis and survival. Am J Cardiol 1972;29:154-63.

28. Thygesen K, Alpert JS, White HD, et al. Universal definition of myocardial infarction. Circulation 2007;116:2634-53.

29. Antman E, Bassand J-P, Klein W, et al. Myocardial infarction redefined-a consensus document of The Joint European Society of Cardiology/American College of Cardiology committee for the redefinition of myocardial infarction. J Am Coll Cardiol 2000;36:959-69.

30. Canada H. Sex and gender-based analysis. Ottawa: Health Canada, 2011.

31. Eckert P, McConnell-Ginet S. Think practically and look locally: language and gender as community- based practice. Annu Rev Anthropol 1992;21:461-90.

32. Cameron D, Coates J. Some problems in the sociolinguistic explanation of sex differences. Lang Commun 1985;5:143-51.

33. World Health Organization W. Gender, women and health. Geneva, Switzerland: WHO, 2011.

34. Harding S. Is there a feminist method? Feminism and Methodology social science issues. Bloomington, Indiana: University of Indiana Press, 1987:1-14.

35. Oakley A. Essays on women, medicine and health. Edinburgh: Edinburgh University Press, 1993:203-20.

36. Ruzek SB, Olesen VL, Clarke A. Women's health: complexities and differences. Columbus: Ohio State University Press, 1997.

37. Charmaz K. Constructing grounded theory, a practical guide through qualitative analysis. London, UK: Sage Publications Ltd, 2006.

38. Russell Bernard H, Ryan G. Analyzing qualitative data systematic approaches. Thousand Oaks, CA: SAGE publications, 2010

39. Kreatsoulas C, Shannon HS, Giacomini M, et al. Reconstructing angina: cardiac symptoms are the same in women and men. JAMA Intern Med 2013;173:829-31.

40. Glaser B, Strauss A. A Discovery of grounded theory: strategies for qualitative research. Chicago, IL: Aldine Publishing Company, 1967.

41. Alter DA, Naylor CD, Austin PC, et al. Biology or bias: practice patterns and long-term outcomes for men and women with acute myocardial infarction. J Am Coll Cardiol 2002;39:1909-16.

42. Hochman JS, Tamis JE, Thompson TD, et al. Sex, clinical presentation, and outcome in patients with acute coronary syndromes. Global Use of Strategies to Open Occluded Coronary Arteries in Acute Coronary Syndromes Ilb Investigators. N Engl $J$ Med 1999;341:226-32.
43. Mikhail GW. Coronary revascularisation in women. Heart 2006;92 (Suppl 3):iii19-23.

44. Mosca L, Appel LJ, Benjamin EJ American Heart Association; American College of Cardiology; American College of Nurse Practitioners; American College of Obstetricians and Gynecologists, et al. Evidence-based guidelines for cardiovascular disease prevention in women. J Am Coll Cardiol 2004;43:900-21.

45. Vaccarino V, Krumholz HM, Berkman LF, et al. Sex differences in mortality after myocardial infarction. Is there evidence for an increased risk for women? Circulation 1995;91:1861-71.

46. Holmes J. Women, language and identity. J Sociolinguistics 1997;1:195-223.

47. Eckert $\mathrm{P}, \mathrm{McC}$ Connell-Ginet $\mathrm{S}$. New generalizations and explanations in language and gender research. Lang Soc 1999;28:185-201.

48. Holmes J, Meyerhoff M. The Community of Practice: theories and methodologies in language and gender research. Lang Soc 1999;28:173-83.

49. Andersson J, Salander P, Brandstetter-Hiltunen M, et al. Is it possible to identify patient's sex when Reading blinded illness narratives? An experimental study about gender bias. Int J Equity Health 2008;7:21.

50. Cameron D. What has gender got to do with sex? Lang Commun 1985;5:19-27.

51. Tannen D. You just Don't understand: men and women in conversation. New York: Morrow; 1990.

52. Seale $\mathrm{C}$, Charteris-Black J. The interaction of class and gender in illness narratives. Sociology 2008;42:453-69.

53. Cameron D. Gender and the language of illness. Soc Health IIIness 2011;33:163-4.

54. Eckert P. The problem with binaries: coding for gender and sexuality. Lang Linguist Compass 2014;8:529-35.

55. Kreatsoulas C, Sloane D, Pogue J, et al. Referrals in acute coronary events for CARdiac catheterization: The RACE CAR trial. Can J Cardiol 2010;26:290-6.

56. Schulman KA, Berlin JA, Harless W, et al. The effect of race and sex on physicians' recommendations for cardiac catheterization. N Engl J Med 1999;340:618-26.

57. Rathore SS, Wang Y, Radford MJ, et al. Sex differences in cardiac catheterization after acute myocardial infarction: the role of procedure appropriateness. Ann Intern Med 2002;137:487-93.

58. Rodgers GP, Conti JB, Feinstein JA, et al. ACC 2009 survey results and recommendations: addressing the cardiology workforce crisis $A$ report of the ACC board of trustees workforce task force. J Am Coll Cardiol 2009;54:1195-208. 